\title{
EARLY OUTCOMES OF FLEXIBLE INTRAMEDULLARY NAILING IN PEDIATRIC SHAFT OF FEMUR FRACTURES
}

\author{
Muhammad Umair Hashmi, Muhammad Nadeem Ahsan, Babar Bakht Chughtai, Saqib Majeed \\ Bahawal Victoria Hospital, Bahawalpur Pakistan, *Nishtar Hospital, Multan
}

\begin{abstract}
Objective: To study the early outcomes and complications of fixation of pediatric shaft of femur fractures using flexible intramedullary nail.

Study Design: Prospective observational study.

Place and Duration of Study: Orthopedic Department, Bahawal Victoria Hospital Bahawalpur, from Jan to Jun 2021.

Methodology: Children between the ages of 5-11 years with shaft of femur fractures were included in the study. Fixation of fracture was done using elastic intramedullary nail. Final outcomes of fixation were observed using Flynn and Schwend Scoring System. Six-month follow-up was done in all cases. Data was analyzed using SPSS-20.

Results: Total 70 cases having shaft of femur fracture were included in the study. Age range of cases was 5-11 years with mean age of $7.75 \pm 1.66$ years and mean weight of $24.44 \pm 4.77$ kilograms. Mean diameter of femur medullary canal was $7.48 \pm 0.63$ millimeters and mean diameter of flexible nail was $3.03 \pm 0.26$ millimeters. Mean post-operative period of radiological union of fracture was $8.57 \pm 1.05$ weeks. Per-operatively, fracture site was approached in $4(5.7 \%)$ cases. Migration of nail was not seen in any case. Final outcomes according to Flynn and Shwend Score were excellent in 62 (88.5\%), satisfactory in $7(10 \%)$ and poor in $1(1.4 \%)$ case.

Conclusion: Fixation of shaft of femur fracture using flexible intramedullary nailing technique is safe and reliable with good outcomes among children between 5-11 years of age.
\end{abstract}

Keywords: Complication, Flexible intramedullary nail, Fracture fixation, Pediatric femur fracture.

How to Cite This Article: Hashmi MU, Ahsan MN, Chughtai BB, Majeed S. Early Outcomes of Flexible Intramedullary Nailing in Pediatric Shaft of Femur Fractures. Pak Armed Forces Med J 2021; 71(6): 2157-2160. Doi: https://doi.org/10.51253/pafmj.v71i6.6137

\footnotetext{
This is an Open Access article distributed under the terms of the Creative Commons Attribution License (https://creativecommons.org/licenses/by-nc/4.0/), which permits unrestricted use, distribution, and reproduction in any medium, provided the original work is properly cited.
}

\section{INTRODUCTION}

Femur fractures constitute $1.6 \%$ of fractures among the children. ${ }^{1}$ Fractures among children put a huge burden not only on the young one, but also on their families. Historically conservative treatment by casting was done among children but due to high complication rate and prolonged immobilization early fixation is recommended. ${ }^{2}$ Since the last two decades there is increasing trend towards operative management so that we may avoid complications and achieve early union of bone, early rehabilitation and mobilization. ${ }^{3}$ Femur fractures are more common in two age groups, one in toddlers and second in adolescents with higher incidence among males than females. Commonly used treatments in diaphyseal femur fractures among children include hip spica cast, elastic intramedullary nail, interlocking nail, external fixation or plate fixation. ${ }^{4}$ External fixation is usually used in open fractures and it is associated with pin tract infection, stiffness of knee and refracture after removal of external fixator, while rigid intramedullary nail is

Correspondence: Dr Muhammad Umair Hashmi, Department of Orthopedic, Bahawal Victoria Hospital, Bahawalpur Pakistan

Received: 01 Jul 2021; revision received: 22 Jul 2021; accepted: 23 Jul 2021 associated with avascular necrosis of femur head and growth plate injury of greater trochanter leading to coxa valga. ${ }^{5}$ Plate fixation of femur fracture needs larger exposure with long incision and more tissue dissection hence causing more blood loss, later on second surgery is needed for plate removal with extensive tissue dissection and increased chances of refracture after plate removal. ${ }^{6}$ Hip spica cast technique is associated with many complications and higher rate of revision surgery of $8 \%$ as compared to $2 \%$ after flexible intramedullary nailing technique. ${ }^{7}$ Fixation of pediatric femur shaft fractures using flexible intramedullary nailing is a simple and minimally invasive technique. ${ }^{8}$ In this technique two flexible nails are inserted into the femur cavity via two entry points on medial and lateral sides just proximal to distal femur growth plate. ${ }^{9}$ Insertion of flexible nails via closed method secure fracture hematoma which promotes fracture healing and early union with low rates of surgical site infection due to minimal invasive method. ${ }^{10}$

As flexible nail is commonly used in pediatric femur fractures, we conducted this study at our hospital to report our experience regarding this technique, to know its early outcomes and associated complications. 


\section{METHODOLOGY}

This was a prospective observational study conducted in Orthopedic Department of Bahawal Victoria Hospital Bahawalpur, from January to June 2021. Study was conducted on 70 cases. Sample size was calculated using WHO sample size formula ( $\mathrm{N}=\mathrm{Z} 2 \mathrm{PQ} /$ D2, where the reference prevalence was $7.5 \%) .{ }^{11}$ Ethical approval was taken from Ethical Review Committee of the study institution (Ref. no. 450/DME/QAMC BWP, dated: 30-11-2020). Informed written consent was taken from all cases in the study group. All cases were admitted in orthopedic ward through emergency department. Sample was selected using non-probability consecutive sampling technique.

Inclusion Criteria: Patients of age 5-11 years, having closed fracture of shaft of femur, not too distal or proximal where intramedullary fixation was not indicated, with visible growth plate on radiographs were included in the study.

Exclusion Criteria: Patients having pathological fractures due to bone tumors or any benign lesion and those with open fractures or neuromuscular disorders were not included in this study.

Initially the fracture was immobilized in all patients and routine workup was done to prepare for surgery. Standard radiographs (antero-posterior and lateral views) of femur were taken including hip and knee joint. Data of patients was documented regarding age, gender, fracture site, weight of patient and narrowest diameter of femur canal measured on anteroposterior and lateral views. Surgeries were done for fixation of fractures after doing complete preoperative workup and planning. Size of flexible intramedullary nail was calculated using Flynn et al. formula as follows: medullary canal narrowest diameter measured on antero-posterior and lateral views both $\times 0.4 \mathrm{~mm} .{ }^{12}$ However nail diameter was slightly changed on peroperative examination of medullary canal as observed on image intensifier. All fractures were done within three days of trauma. Surgery was done under general anesthesia, on fracture table with the guidance of image intensifier. Retrograde approach was used for insertion of flexible nails. A small incision was given 1$2 \mathrm{~cm}$ proximal to distal femoral epiphysis and a small bone window was formed for the entry of nail on medial and lateral side of femur shaft. Flexible nail was inserted into the femur through bone window negotiating fracture site and confirmed on image intensifier. Titanium made flexible nails were used with range of size from 2.5-3.5 mm. Alignment of femur was ensured in all three planes per-operatively. Data were documented related to nail diameter, duration of surgery and total duration of hospital stay. Patients were discharged with immobilization splint and follow-up was done on weekly basis for two weeks then followed by two weeks' follow-up. A total of six months' follow-up was done. Gradual weight bearing was started after achieving radiological union. Wounds were assessed for surgical site infection on first follow-up after one week. After two weeks, immobilization splint was removed and movement on joints was started to prevent joint stiffness. Post-operative complications were recorded like surgical site infection, malunion, angulation of bone (5-10 degrees) and limb length discrepancy (1$2 \mathrm{~cm}$ ). Flynn and Schwend Scoring System was used to grade final outcomes in terms of excellent, good and poor. ${ }^{13}$

Data were analyzed using Statistical Package for Social Sciences (SPSS) version 23. Means and standard deviation were determined for quantitative variables. Frequency and percentages were determined for qualitative variables.

\section{RESULTS}

Total 70 cases were included in the study. There were $46(65.7 \%)$ males and $24(34.3 \%)$ females. Mean weight of patients was $24.44 \pm 4.77$ kilograms with minimum weight of $15 \mathrm{kgs}$ and maximum weight of $38 \mathrm{kgs}$. Common pattern of femur shaft fracture was transverse in $53(75.7 \%)$ cases followed by oblique in 12 $(17.1 \%)$, spiral in $3(4.3 \%)$ and comminuted fracture in $2(2.8 \%)$ cases (Table). Mean femoral canal diameter was $7.48 \pm 0.63 \mathrm{~mm}$ and mean nail diameter was $3.03 \pm$ $0.26 \mathrm{~mm}$. Mean duration of surgery was $48.71 \pm 8.87$ minutes and mean duration of hospital stay was $2.11 \pm$ 0.57 days. Mean time for radiological union was $8.57 \pm$ 1.05 weeks.

Table: Demographics of femur fractures treated $(n=70)$.

\begin{tabular}{|c|c|}
\hline Parameters & n (\%) \\
\hline \multicolumn{2}{|l|}{ Fracture site } \\
\hline Middle shaft & $47(67.1 \%)$ \\
\hline Distal shaft & $13(18.6 \%)$ \\
\hline Proximal Shaft & $10(14.3 \%)$ \\
\hline \multicolumn{2}{|l|}{ Gender } \\
\hline Male & $46(65.7 \%)$ \\
\hline Female & $24(34.3 \%)$ \\
\hline \multicolumn{2}{|l|}{ Fracture Pattern } \\
\hline Transverse & $53(75.7 \%)$ \\
\hline Oblique & $12(17.1 \%)$ \\
\hline Spiral & $3(4.3 \%)$ \\
\hline Comminuted & $2(2.9 \%)$ \\
\hline
\end{tabular}


Age range of patients was 5-11 years with mean age of $7.75 \pm 1.66$ years. There were $18(25.7 \%)$ cases between 5-6 years, 29 (41.4\%) between 7-8 years and 23 $(32.8 \%)$ between $9-10$ years of age (Figure-1).

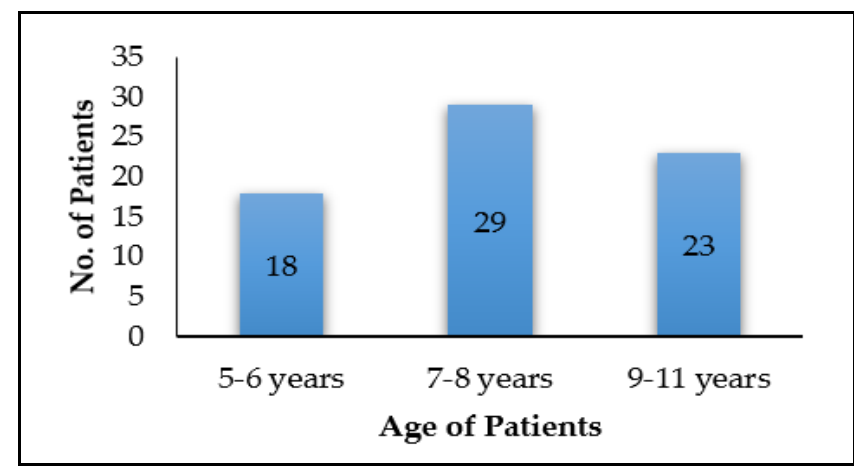

Figure-1: Age distribution of patients in study group.

According to Flynn and Schwend Scoring Systems final outcomes were assessed on six months' follow-up and graded as excellent in maximum cases $62(88.5 \%)$, satisfactory in $7(10 \%)$ and poor outcomes in $1(1.4 \%)$ case (Figure-2).

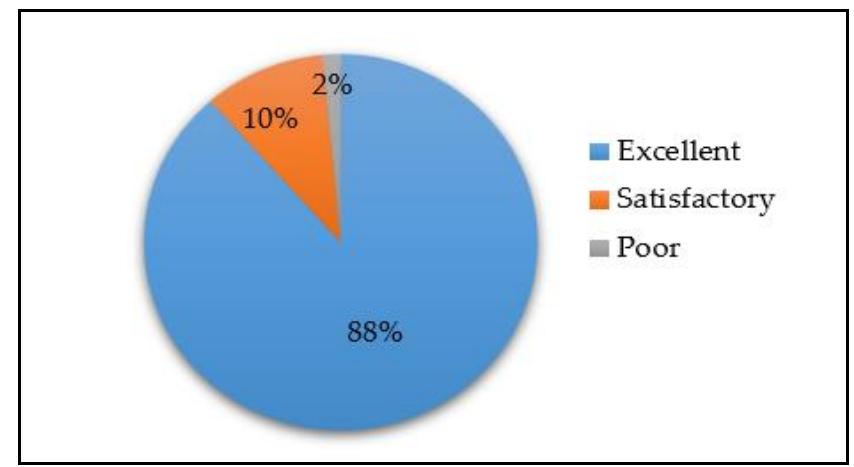

Figure-2: outcomes in terms of Flynn \& Schwend Score 10.

Complications were reported in $11(15.7 \%)$ cases including need to approach fracture site per-operatively in $4(5.7 \%)$ cases followed by limb length discrepancy of $1-2 \mathrm{~cm}$ in $3(4.3 \%)$ cases. Malunion was reported in one case only. Limb length discrepancy of $>2 \mathrm{~cm}$ and migration of nail were not reported in any case (Figure-3).

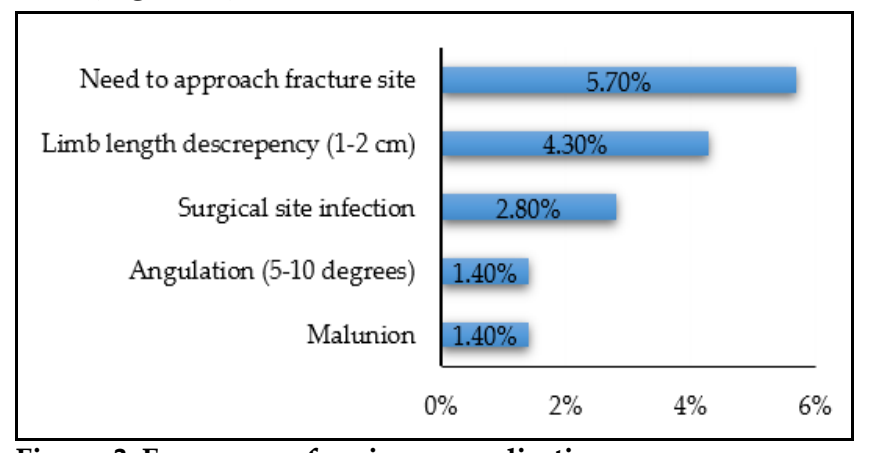

Figure-3: Frequency of various complications.

\section{DISCUSSION}

Growing bones have the natural ability of heal and remodel after fractures so much so that radiologically even the sign of fracture vanishes. With the development of implants for fixation of fractures we can achieve more accurate fixation of bones earlier with less chances of malunion. Flexible nail was introduced by Nancy group in 1982 due to its better outcomes, simple to use with less complications. ${ }^{14}$ In our study children with 5-11 years of age having shaft of femur fractures were operated for fixation of fracture with flexible intramedullary nail. Allen et al and Lindisfarne and Ayodele in their studies, reported superior outcomes of intramedullary flexible nail than plate fixation in femoral shaft fractures among children with age of 5-11 years. ${ }^{11,15}$ Alberghina et al, conducted a study on 24 cases and $20(83.3 \%)$ out of them had excellent outco-mes and no case had angulation $>10$ degrees. ${ }^{16}$ In our study $88.5 \%$ cases showed excellent outcomes and just one case $(1.4 \%)$ reported with angulation $<10$ degrees while no case reported with angulation $>10$ degrees. A study conducted in India by Ghilley et al. on fixation of femoral shaft fractures using flexible nails reported mean time of radiological union of 8 weeks in $92.8 \%$ cases. ${ }^{17}$ These results are comparable with our study in which mean time of radiological union was $8.57 \pm 1.05$ weeks. A study conducted in Croatia on 103 cases with femoral shaft fractures treated with flexible intramedullary nailing, union was achieved in mean time of 8.5 weeks with complication rate of $8.49 \%$ and major complication of entry site skin irritation reported in $2.9 \%$ cases. ${ }^{18}$ In our study complication rate was $15.7 \%$. This relatively high complication rate is due to many factors such as lack of advanced healthcare facilities as provided in developed countries, surgeon factor, mode of injury and patient's compliance to the instructions provided to them regarding care of operated limb etc. In a study conducted by Bilal et al, most of the patients $(52.7 \%)$ were between $5-8$ years of age and they repor-ted no difference in union rate among male and female patients. ${ }^{19}$ Similarly in our study sample maximum patients $(67.1 \%)$ were between 5-8 years of age and we did not find any difference in union rate among male and female patients. A study conducted in USA by Neilson et al, on 54 children to see outcomes of flexible nail fixation in femoral shaft fractures found malunion in $5.5 \%$ cases, ${ }^{20}$ while in our study, malunion was seen in one case $(1.4 \%)$ only. High rate of malunion is associated with length unstable fractures, comminuted fractures and increased body weight more than $49 \mathrm{~kg} .{ }^{21,22}$ In our study 
mean body weight was $24.44 \pm 4.77 \mathrm{~kg}$ and maximum weight was $36 \mathrm{~kg}$. Reduced rate of malunion in our study was due to strict inclusion criteria.

Further studies should be done in our region to see long term outcomes especially on older and heavy weight children to evaluate outcomes of this novel technique.

\section{LIMITATION OF STUDY}

Limitation of this study was that it was been conducted in a single center with small sample size and follow-up was done for limited period of time.

\section{CONCLUSION}

Flexible intramedullary nail technique is safe and reliable for fixation of femur shaft fractures among children in the age group of 5-11 years. It has less complications, early recovery with very good union rate and excellent early outcomes. It is a simple technique and easy to perform under image intensifier. Further studies are required to prove good results of this novel technique as operative treatment of pediatric femur fractures is becoming popular now.

\section{Conflict of Interest: None.}

\section{Authors' Contribution}

MUH: Conception, data collection, MNA: Data analysis, BBC: Data collection, SM: Drafting, data collection.

\section{REFERENCES}

1. Muzzafar K, Singh R, Bhat SA, Haseeb M, Ghani A. Early result of pediatric shaft femur fractures treated by hip spica cast in children upto 10 years of age. Int J Res Med Sci 2017; 5(6): 2430.

2. Dial BL, Lark RK. Pediatric proximal femur fractures. J Orthop 2018; 15(2): 529-535.

3. Sessions WC, Nickel AJ, Truong WH, McMahon RD, Finch MD, Georgiadis AG. Regionalization of isolated pediatric femur fracture treatment: recent trends observed using the Kids' Inpatient Database. J Pediatr Orthop 2020; 40(6): 277-282.

4. Frei B, Mayr J, de Bernardis G, Camathias C, Holland-Cunz S, Rutz E. Elastic stabile intramedullary nailing (ESIN) of diaphyseal femur fractures in children and adolescents: a strobe-compliant study. Med 2019; 98(14): 1-5.

5. Kirmani TT, Huda N, Mishra G. Osteosynthesis of pediatric femoral shaft fractures with flexible intramedullary nailing-experience from developing world. Int J Burn Trauma 2020; 10(4): $127-130$.

6. Govindasamy R, Gnanasundaram R, Saravanan Kasirajan SI, Melepuram JJ. Elastic stable intramedullary nailing of femoral shaft fracture-experience in 48 children. Arch Bone Jt Surg 2018; 6(1): 39-42.

7. Brnjos K, Lyons DK, Hyman MJ, Patel NM. Spica casting results in more unplanned reoperations than elastic intramedullary nailing: a national analysis of femur fractures in the preschool population. J Am Acad Orthop Surg Glob Res Rev 2020; 4(10): e20.
8. Shaha JS, Cage JM, Black SR, Wimberly RL, Shaha SH, Riccio AI. Redefining optimal nail to medullary canal diameter ratio in stainless steel flexible intramedullary nailing of pediatric femur fractures. J Pediatr Orthop 2017; 37(7): e398-e402.

9. Makarewich CA, Talwar D, Baldwin KD, Swarup I. Flexible intramedullary nailing of femoral shaft fractures in children weighing $\geq 40 \mathrm{~kg}$ : a systematic review and meta-analysis. J Pediatr Orthop 2020; 40(10): 562-568.

10. Marengo L, Nasto LA, Michelis MB, Boero S. Elastic stable intramedullary nailing (ESIN) in paediatric femur and tibia shaft fractures: comparison between titanium and stainless steel nails. Injury 2018; 49(1): S8-11.

11. Allen JD, Murr K, Albitar F, Jacobs C, Moghadamian ES, Muchow R. Titanium elastic nailing has superior value to plate fixation of Midshaft femur fractures in children 5 to 11 years. J Pediatr Orthop 2018; 38(3): e111-e117.

12. Flynn JM, Hresko T, Reynolds RA, Blasier RD, Davidson R, Kasser J. Titanium elastic nails for pediatric femur fractures: a multicenter study of early results with analysis of complications. J Pediatr Orthop 2001; 21(1): 4-8.

13. Garg P, Saxena S, Hamid FB, Somashekarappa T. Study to assess the functional outcome of Intramedullary titanium elastic nails in the paediatric lower limb long bone fractures. Int J Health Clin Res 2020; 3(8): 173-178.

14. El-Sayed AS. Treatment of the femoral shaft fractures in children by a single elastic stable intramedullary nail. Egypt Orthop J 2018; 53(1): 83-86.

15. Lindisfarne EA, Ayodele O. Non-accidental injury, femoral shaft and neck fractures in children. Orthop Trauma 2018; 32(5): 306318.

16. Alberghina F, Andreacchio A, Cravino M, Paonessa M, Canavese F. Extra-articular proximal femur fractures in children and adolescents treated by elastic stable intramedullary nailing. Int Orthop 2019; 43(12): 2849-2856.

17. Ghilley SK, Meena MK, Jhanwar P, Jain HK. Use of flexible intramedullary nailing in treating diaphyseal fractures of long bone of lower limb in children. J Orthop Trauma Rehabilit 2019; 11(1): 21-25.

18. Pogorelić Z, Vodopić T, Jukić M, Furlan D. Elastic stable intramedullary nailing for treatment of pediatric femoral fractures; a 15-year single centre experience. Bull Emerg Trauma 2019; 7(2): 169-172.

19. Bilal M, Sarfraz M, Ahmad S, Saidullah A, Ayaz M, Zimri FU. Radiological and functional outcomes of flexible intramedullary nailing in children with open tibial fractures. Med Forum Mon 2020; 31(8): 106.

20. Nielsen E, Andras LM, Bonsu N, Goldstein RY. The effects of body mass index on treatment of paediatric femur fractures managed with flexible intramedullary nails. J Child Orthop 2017; 11(5): 393-397.

21. Andreacchio A, Alberghina F, Marengo L, Canavese F. Pediatric tibia and femur fractures in patients weighing more than $50 \mathrm{~kg}$ $(110 \mathrm{lb})$ : mini-review on current treatment options and outcome. Musculoskelet Surg 2019; 103(1): 23-30.

22. Nielsen E, Andras LM, Bonsu N. The effects of body mass index on treatment of paediatric femur fractures managed with flexible intramedullary nails. J Child Orthop 2017; 11(5): 393-397.

23. Parekh MN. Treatment of Paediatric Femoral Shaft Fracture with Flexible Intramedullary Nail. J Surg Pak 2020; 25(1): 13-17. 